\title{
Transient receptor potential canonical 5 channel is involved in the cardiac damage related to obstructive sleep apnea-hypopnea syndrome in rats
}

\author{
Wen Wen ${ }^{1 \#}$, Qiaoling Yao ${ }^{2 \#}$, Yulan Chen ${ }^{1}$, Zhiqiang Li $^{3}$, Bumairemu Maitikuerban ${ }^{1}$, Yu Zhang ${ }^{1}$, \\ Junshi Zhang ${ }^{1}$, Zhulepiya Simayi ${ }^{1}$, Xinjuan $\mathrm{Xu}^{1}$, Xiangyang Zhang ${ }^{1}$ \\ ${ }^{1}$ Department of Hypertension, The First Affiliated Hospital of Xinjiang Medical University, Urumqi 830054, China; ${ }^{2}$ Department of Physiology, \\ Preclinical Medicine Collage of Xinjiang Medical University, Urumqi 830011, China; ${ }^{3}$ Clinical Medical Research Institute, The First Affiliated \\ Hospital of Xinjiang Medical University, Urumqi 830054, China \\ Contributions: (I) Conception and design: W Wen, Q Yao, Y Chen; (II) Administrative support: Y Chen; (III) Provision of study material or patients: \\ All authors; (IV) Collection and assembly of data: All authors; (V) Data analysis and interpretation: W Wen, Q Yao; (VI) Manuscript writing: All \\ authors; (VII) Final approval of manuscript: All authors. \\ "These authors contributed equally to this work. \\ Correspondence to: Yulan Chen. Department of Hypertension, The First Affiliated Hospital of Xinjiang Medical University, Urumqi 830054, China. \\ Email: sheliachen@sina.com.
}

Background: Obstructive sleep apnea-hypopnea syndrome (OSAHS) is recognized as an independent risk factor of cardiovascular disease. The release of $\mathrm{Ca}^{2+}$ mediated by transient receptor potential canonical (TRPC) channels participates in the hypoxia-induced pathophysiological changes in the cardiovascular systems in case of OSAHS. This study aimed to investigate which subtypes of TRPCs were involved in OSAHS in a rat model of intermittent hypoxia.

Methods: OSAHS was induced by exposure of rats to intermittent hypoxia. The expression of TRPCrelated genes and proteins in the cardiomyocytes by qRT-PCR and Western Blotting, respectively.

Results: The mRNA expression of TRPC3/TRPC4/TRPC5 increased significantly in OSAHS group compared with the control group $(\mathrm{P}<0.05)$. The TRPC5 protein expression was significantly higher in the OSAHS control than the control group $(\mathrm{P}<0.05)$.

Conclusions: The TRPC5 channel is likely to be involved in the OSAHS induced pathophysiological changes in the myocardium and may become a target to prevent OSAHS related cardiac damage.

Keywords: Obstructive sleep apnea-hypopnea syndrome (OSAHS); intermittent hypoxia; transient receptor potential canonical; calcium; cardiomyocytes

Submitted Sep 26, 2019. Accepted for publication Feb 10, 2020.

doi: 10.21037/apm.2020.04.08

View this article at: http://dx.doi.org/10.21037/apm.2020.04.08

\section{Introduction}

Obstructive sleep apnea-hypopnea syndrome (OSAHS) as an independent risk factor for cardiovascular diseases is closely related to the development of many cardiovascular diseases such as left ventricular remodeling (1), vascular endothelial injury (2), coronary heart disease, congestive heart failure (3), and arrhythmia (4,5). It is well known that the intermittent hypoxia is involved in the pathogenesis of
OSAHS. Hypoxia may activate the sympathetic nerves and the renin angiotensin-aldosterone system (RAAS), leading to the vasoconstriction and subsequent hypertension. In addition, the fluctuation of intrathoracic negative pressure due to obstruction of the upper airway causes the mechanical and hemodynamic changes that may alter the cardiac output. These pathophysiological changes eventually cause oxidative stress. Granger et al. (6) found that oxidative 
stress was involved in the ischemia-reperfusion injury of the heart disease.

Oxidative stress produces excessive reactive oxygen species (ROS). In normal aerobic metabolism, the balance between oxidation and reduction is dynamically maintained. However, the imbalance between them may disrupt the antioxidant defense and lead to the excessive formation of ROS (7). At the same time, oxidative stress can selectively activate the pro-inflammatory pathways (8). ROS and inflammatory mediators can act together on myocardial subcellular structures such as proteins, nucleic acids, and mitochondria, causing myocardial metabolic dysfunction and structural changes. In the pro-inflammatory pathways, $\mathrm{Ca}^{2+}$ is an important regulator of ROS production (9), and mitochondria is a known pool of calcium. The reduced $\mathrm{Ca}^{2+}$ concentration in the mitochondria leads to a decreased ATP production, while the $\mathrm{Ca}^{2+}$ overload in the mitochondria may cause excessive ROS production, resulting in a series of myocardial pathophysiological changes (10). Oxidative stress induced by intermittent hypoxia can induce endoplasmic reticulum stress by activating the angiotensin IIphospholipase C-trisphosphate (AngII-PLC-IP 3 ) pathway, which induces the release of $\mathrm{Ca}^{2+}$ from the endoplasmic reticulum into the cytosol and leads to $\mathrm{Ca}^{2+}$ imbalance (11).

The transient receptor potential canonical (TRPC) channel is a classical calcium channel widely distributed in mammalian cells, but the TRPC2 is not expressed in humans (12). In recent years, increasing attention has been paid to the physiological and pathological roles of TRPCs due to its wide expression (13). Some studies have found that the activation of TRPC channels is closely related to the occurrence and development of cardiovascular diseases. For example, TRPC1 is involved in the proliferation, migration and apoptosis of vascular smooth muscle cells (14-17); TRPC3 expression is associated with the hypertension (18), atrial fibrillation (19), arrhythmia, cardiomyocyte hypertrophy (20) and myocardial fibrosis (19). The expression of TRPC4 channel increases in the endothelial cells (21,22). TRPC6 is involved in the process of myocardial hypertrophy (20) and myocardial ischemiareperfusion injury (23). Recently, TRPC7 has been found to be also involved in the myocardial ischemiareperfusion injury (23). Thus, TRPCs are closely related to the pathogenesis of cardiovascular diseases including the OSAHS induced cardiovascular diseases. To investigate the role of TRPC in the pathogenesis of OSAHS, a rat model of
OSAHS was established by intermittent hypoxic exposure, and the protein and mRNA expressions of TRPCs were detected in the heart by Western Blotting and qRT-PCR, respectively.

\section{Methods}

\section{Animal model}

This study was approved by the Ethics Committee of Xinjiang Medical University (IACUC-20170214045). Sprague Dawley rats (SD rats) were provided by the Experimental Animal Center of Xinjiang Medical University. Eighteen male SD rats, 15-17 w of age (at the time of surgery) were used in the present study. Animals were housed for 1 week before experiment and then randomly assigned to the experimental group $(n=9)$ and the control group $(n=9)$. In the experimental group, rats were placed in a chamber and exposed to intermittent hypoxia for $8 \mathrm{~h}$ (10AM-6PM) once daily. In the hypoxic exposure, rats were exposed to $8.5 \%$ oxygen for $1 \mathrm{~min}$ and then air $(21 \%$ oxygen) for $1 \mathrm{~min}$. Blood gas analysis was performed after 4 weeks $(24,25)$ : the arterial oxygen partial pressure was 20.9-29.7 $\mathrm{mmHg}$, the blood oxygen saturation was $31.2-58.3 \%$, and the blood oxygen partial pressure was $71.6 \mathrm{mmHg}$ when they were exposed to air (21\% oxygen). $106.4 \mathrm{mmHg}$, blood oxygen saturation was 92.2-97.4\%, which was in line with the diagnostic criterion for human severe OSAHS $\left(\mathrm{SaO}_{2}<80 \%\right)$. Among then, 1 rat in the experimental group and one rat in the control group died in the experiment. After hypoxic exposure, the rats were sacrificed and the hearts were harvested for detection of TRPC expressions.

\section{Real-time PCR relative quantitation of cardiomyocytes}

The heart tissues $(25-50 \mathrm{mg})$ were homogenized and total RNA extracted with $1 \mathrm{~mL}$ of Trizol. Then, $2 \mu \mathrm{L}$ of RNA was reversely transcribed into cDNA, which served as templates for amplification. The primers used in the PCR were synthesized in the Ouyi Biotech Co., Ltd in Xinjiang Province (Table 1).

PCR was performed as follows: pre-denaturation at $95^{\circ} \mathrm{C}$ for $2 \mathrm{~min}, 40$ cycles of denaturation at $95^{\circ} \mathrm{C}$ for $5 \mathrm{~s}$, annealing at $60{ }^{\circ} \mathrm{C}$ for $30 \mathrm{~s}$ and extension at $60{ }^{\circ} \mathrm{C}$ for $30 \mathrm{~s}$. The PCR products $(10 \mu \mathrm{L})$ were subjected to $1.8 \%$ agarose gel electrophoresis at $150 \mathrm{~V}$ for $10 \mathrm{~min}$ (26-28). 
Table 1 Primers used for the amplification of TRPC genes

\begin{tabular}{lcc}
\hline Primers & Sequences (5' to 3') & Size \\
\hline TRPC1-F & CTGCTTATCTTCATGTGCGGTC & $138 \mathrm{bp}$ \\
TRPC1-R & GAAGCTGTGGTAGGCTCTGT & \\
TRPC3-F & ACGCAGTACGGCAACATC & $209 \mathrm{bp}$ \\
TRPC3-R & CGCACATAGCCTTTGCTGAT & \\
TRPC4-F & AAGGATTAGCTTCACGGGGTG & $198 \mathrm{bp}$ \\
TRPC4-R & CCTCCTCCTGGGCGTGTTC & \\
TRPC5-F & CCATACAGAGACCGCATCCC & $283 \mathrm{bp}$ \\
TRPC5-R & CCTTGCGGATGGCATAGAGT & \\
TRPC6-F & AAACAGACTGACTCACCGGC & $238 \mathrm{bp}$ \\
TRPC6-R & CGCCAACTGTAGGGCATTCT & \\
TRPC7-F & TTGGGGAGCAACACCTTCAA & $97 \mathrm{bp}$ \\
TRPC7-R & TGAACATGTAGGCAGGACCC & \\
GAPDH-F & CAGGGCTGCCTTCTCTTGTG & $172 \mathrm{bp}$ \\
GAPDH-R & GATGGTGATGGGTTCCCGT & \\
\hline
\end{tabular}

\section{Western blotting}

The heart tissues were homogenized and lysed in $40 \mu \mathrm{L}$ of RIPA with protease inhibitor (AR0105; Boster), and then the homogenate was centrifuged at $12,000 \mathrm{rpm}$ for $15 \mathrm{~min}$ at $4{ }^{\circ} \mathrm{C}$. The supernatant was collected, and the protein concentration was determined with BCA method (DQ111-01). Then, the proteins were mixed with $5 \times$ SDS-PAGE loading buffer (containing $\beta$-mercaptoethanol), and the mixture was boiled at $100{ }^{\circ} \mathrm{C}$ for $5 \mathrm{~min}$ to denatured proteins. Then, the mixture was centrifuged at $12,000 \mathrm{rpm}$ for $5 \mathrm{~min}$. The supernatant was collected and subjected to electrophoresis (12\% separating gel and 5\% stack gel, followed by protein transferring at $300 \mathrm{~mA}$ for $2 \mathrm{~h}$. The membrane was blocked in $5 \%$ non-fat milk for $1 \mathrm{~h}$ at room temperature and then incubated with primary antibody at $4{ }^{\circ} \mathrm{C}$ over night (anti-rabbit TRPC6 (D3G1Q; 1:500; CST, anti-TRP 7 (N64A/36; 1:500, CST), anti-TRPC5 (1C8; 1:100, Santa cruz). The membrane was washed in TBS-T (PH 7.6) and then incubated with horseradish peroxidase conjugated secondary antibody, followed by visualization with enhanced chemiluminescence. The protein bands were scanned and analyzed with AlphaEaseFC 4.0 software. The expressions of TRPC1, TRPC 3 and TRPC4 were undetectable, but the expressions of TRPC5, TRPC6 and TRPC7 were detectable.

\section{Statistical analysis}

Data are reported as mean \pm standard error $(\mathrm{SEM})$. The statistical analysis was performed with SPSS version 19.0 (IBM). The independent sample $T$ test for data with normal distribution and the rank sum test for data with abnormal distribution were used for comparisons between groups. A value of $\mathrm{P}<0.05$ was considered statistically significant.

\section{Results}

\section{$m R N A$ expression of TRPC}

The results in Table 2 indicate that the ratio of RNA sample A260/A280 is an RNA purity test method, and RNA samples with a ratio ranging from 1.8 to 2.1 are considered acceptable. The sample of HVL213, HVL215, HVL216 of normal group and HVL201, HVL202, HVL203, HVL205, HVL206, HVL209 of test group were qualified. Figure 1 shows that in the electrophoresis chart, $28 \mathrm{~S}$ and $18 \mathrm{~S}$ have higher brightness, $5 \mathrm{~S}$ is weakest or no band, and the band is single intact, which is regarded as a qualified RNA sample. As shown in Figure 2, the expression of TRPC3, TRPC4, and TRPC5 in the OSAHS group was significantly higher than in the control group $(\mathrm{P}<0.05)$. 
Table 2 mRNA expression of different TRPC genes

\begin{tabular}{lccccccccc}
\hline No. & Sample grouping & Sample number & $260 \mathrm{~nm}$ & $280 \mathrm{~nm}$ & $230 \mathrm{~nm}$ & $260 / 280$ & $260 / 230$ & C: ng/uL & Eligibility \\
\hline 1 & Normal group & HVL213 & 5.44 & 2.96 & 6.51 & 1.84 & 0.84 & 217.49 & Qualified \\
2 & & HVL216 & 1.86 & 1.03 & 1.34 & 1.80 & 1.39 & 74.45 & Qualified \\
3 & Test group & HVL201 & 6.96 & 3.57 & 4.56 & 1.95 & 1.53 & 278.58 & Qualified \\
4 & & HVL202 & 5.43 & 2.87 & 5.32 & 1.89 & 1.02 & 217.24 & Qualified \\
5 & & HVL203 & 7.28 & 3.72 & 4.56 & 1.96 & 1.60 & 291.30 & Qualified \\
6 & & HVL205 & 6.04 & 3.15 & 4.36 & 1.92 & 1.39 & 241.58 & Qualified \\
7 & & HVL206 & 7.27 & 3.71 & 6.12 & 1.96 & 1.19 & 290.90 & Qualified \\
8 & & HVL209 & 8.96 & 4.64 & 6.37 & 1.93 & 1.41 & 358.54 & Qualified \\
9 & Normal group & HVL215 & 8.80 & 4.49 & 4.53 & 1.96 & 1.94 & 351.91 & Qualified \\
\hline
\end{tabular}

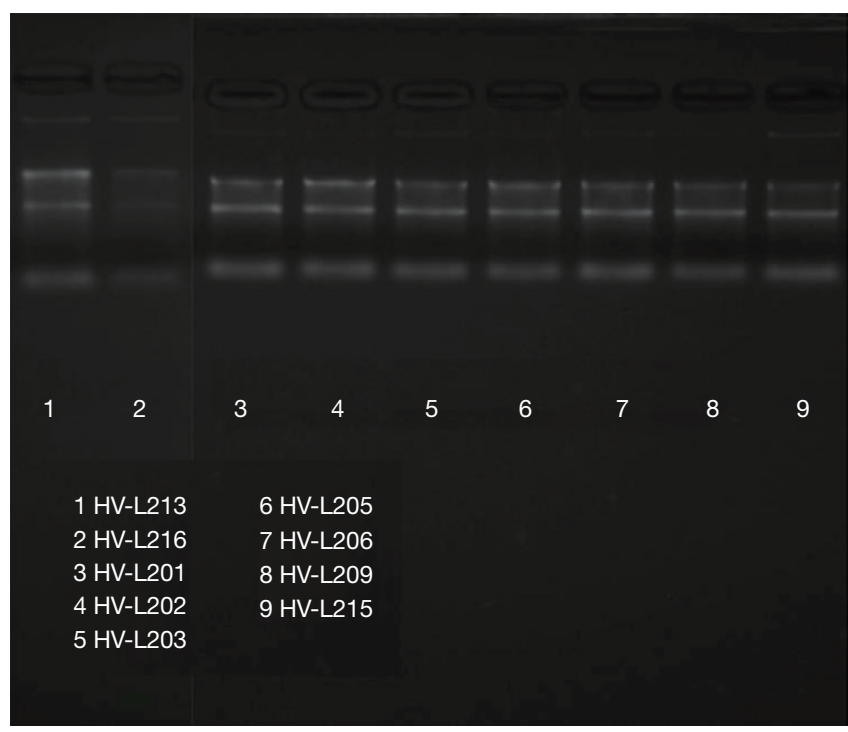

Figure 1 RNA electropherogram.

\section{Protein expression of TRPC by Western-blot}

The protein sample concentration value was greater than $5.0 \mu \mathrm{g} / \mu \mathrm{L}$ and the protein concentration is acceptable (Table 3). Table 4 suggests that the expression of TRPC5 protein in the heart tissue of OSAHS rats was statistically significant $(\mathrm{P}<0.05)$ (Figure 3).

\section{Discussion}

TRPC5 channel is one of TRPC channels. It is not only a non-selective cation channel with four specific structures, but also a non-voltage-gated cation channel mainly permeable to $\mathrm{Ca}^{2+}$. TRPC5 mainly regulates the permeability of microcirculation vessels to intracellular free $\mathrm{Ca}^{2+}$ (29). The TRPC5 channel is mapped to q23 in the human $\mathrm{X}$ chromosome and mainly expressed in the central nervous system, kidney and cardiovascular system (30). The activation of TRPC5 channel via the phospholipase C (PLC) signaling pathway is its primary mechanism of action. Upon binding of the agonist to the G-protein coupled receptor or tyrosine receptor, the PLC is activated to hydrolyze phosphatidylinositol bisphosphate $\left(\mathrm{PIP}_{2}\right)$ to produce inositol trisphosphate $\left(\mathrm{IP}_{3}\right)$ and diacylglycerol (DAG), and then the DAG can be metabolized to arachidonic acid and linolenic acid. The $\mathrm{IP}_{3}$ acts on the endoplasmic reticulum or sarcoplasmic reticulum causing $\mathrm{Ca}^{2+}$ release in the calcium reservoir. When the calcium depletion is exhausted, the TRPC channel on the cell membrane is activated to initiate $\mathrm{Ca}^{2+}$ influx. This is called calcium influx of the calcium reservoir manipulation, the loaded channel is store-operated $\mathrm{Ca}^{2+}$ channel (SOCC), and TRPC5 channel is a kind of store-operated $\mathrm{Ca}^{2+}$ channel (31). In recent years, some studies have focused on the role of TRPC5 channel in the pathogenesis of diseases of the kidney $(32)$, tumor $(33,34)$ and nerve $(35,36)$. Studies have shown that TRPC5 channels are involved in the proliferation, contraction, migration, and hypertrophy of vascular smooth muscle cells (37). $\mathrm{Ca}^{2+}$ is an important regulator of ROS production, and $\mathrm{Ca}^{2+}$ overload in the mitochondria can lead to excessive ROS production and cause a series of myocardial pathophysiological changes.

In this study, a rat model of OSAHS was established via intermittent hypoxia (IH) exposure, and the mRNA and protein expressions of different TRPCs were detected in 


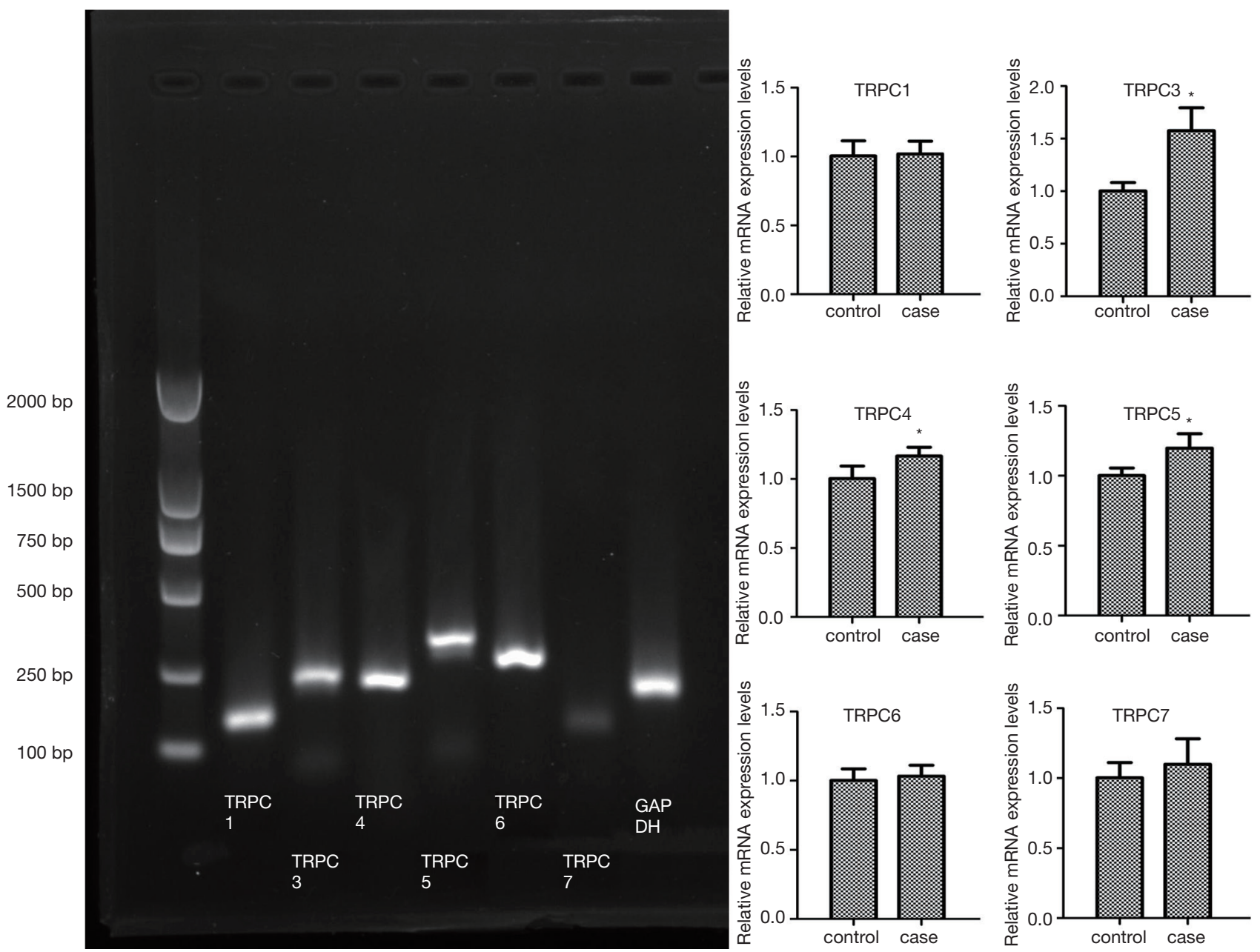

Figure 2 PCR primer identification electropherogram. *, $\mathrm{P}<0.05$.

Table 3 Protein concentration table (part)

\begin{tabular}{lccccccc}
\hline $\begin{array}{l}\text { Sample } \\
\text { number }\end{array}$ & OD1 & OD2 & OD3 & OD mean & OD blank & $\begin{array}{c}\text { Post-dilution concentration } \\
(\mu \mathrm{g} / \mathrm{mL})\end{array}$ & $\begin{array}{c}\text { Predilution concentration } \\
(\mu \mathrm{g} / \mu \mathrm{L})\end{array}$ \\
\hline HV-L201 & 1.353 & 1.366 & 1.374 & 1.360 & 1.244 & 1287.778 & 12.878 \\
HV-L202 & 1.528 & 1.540 & 1.552 & 1.534 & 1.418 & 1481.667 & 14.817 \\
HV-L203 & 1.520 & 1.531 & 1.541 & 1.526 & 1.410 & 1472.222 & 14.722 \\
\hline
\end{tabular}

Table 4 Western-blot analysis of protein expression in cardiac tissue of rats with obstructive sleep apnea syndrome $\left(\bar{x}_{ \pm s}, \mathrm{n}=8\right)$

\begin{tabular}{lccr}
\hline Group & TRPC6 & TRPC7 & TRPC5 \\
\hline Normal group & $1.460 \pm 0.537$ & $6.030 \pm 0.675$ & $6.822 \pm 1.909$ \\
Test group & $1.530 \pm 0.767$ & $5.028 \pm 1.836$ & $11.448 \pm 2.601$ \\
T & -0.137 & 0.886 & -2.648 \\
P & 0.896 & 0.410 & 0.038 \\
\hline
\end{tabular}




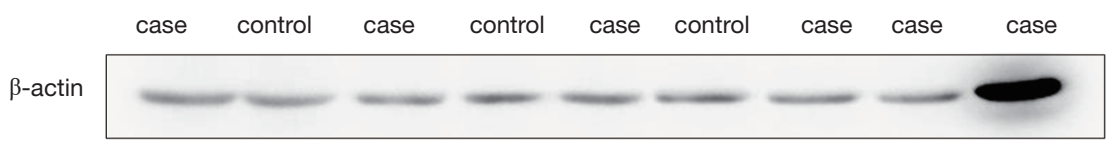

\section{Heart tissue}

TRPC5
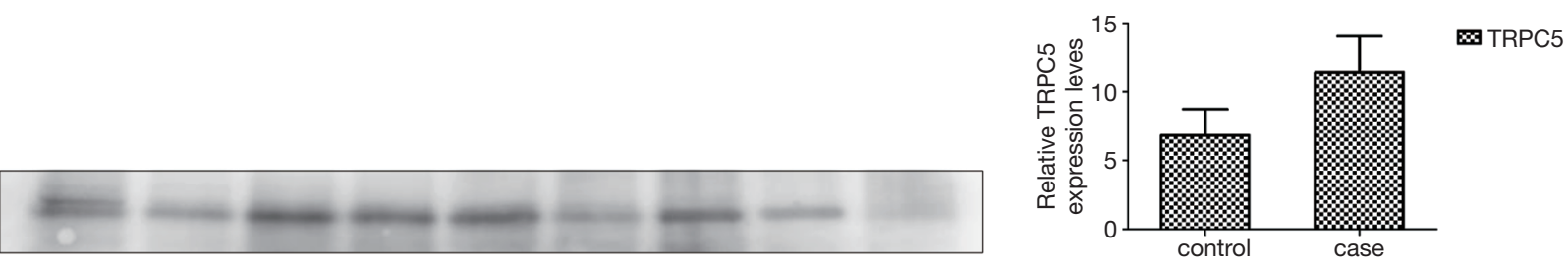

TRPC6
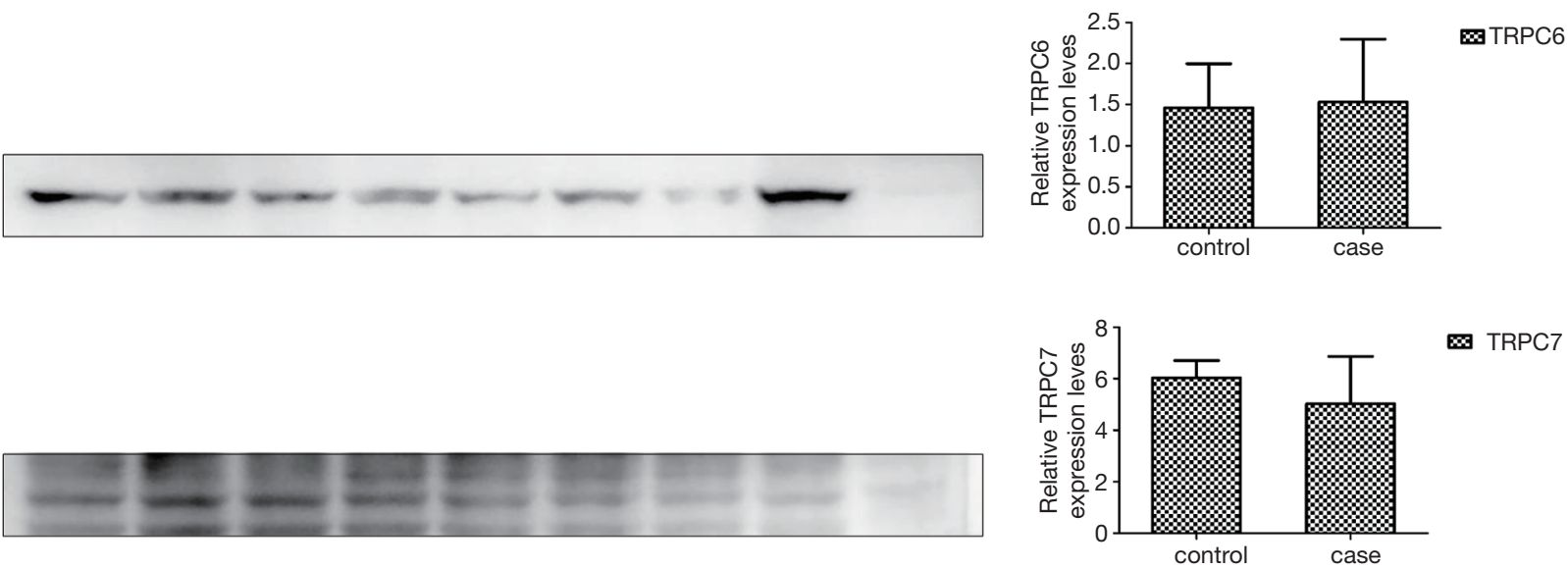

TRPC7

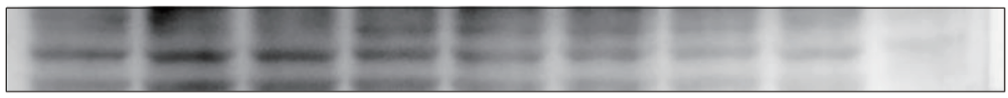

control

case

Figure 3 Expression of TRPC5 protein in the heart tissue of OSAHS rats.

the heart.

Results showed the mRNA expression of TRPC3 (normal group $1.002 \pm 0.080$, experimental group $1.576 \pm 0.218$ ), TRPC4 (normal group $1.003 \pm 0.092$, experimental group $1.167 \pm 0.063$ ), and TRPC5 (normal group 1.001 \pm 0.055 , experimental group1.198 \pm 0.102$)$ in the heart tissues of OSAHS group was significantly higher than in the control group $(\mathrm{P}<0.05)$. This suggests that the intermittent hypoxia may affect the mRNA expression of TRPC3/TRPC4/ TRPC5 in rat heart.

Furthermore, the protein expression of different TRPCs was also detected in the heart tissues of rats after intermittent hypoxia exposure. The protein expression of TRPC1/TRPC3/TRPC4 was undetectable in two groups, but that of TRPC5/TRPC6/TRPC7 was detectable in both groups. Our results showed the protein expression of TRPC5 in the heart of the OSAHS group was significantly different between two groups $(\mathrm{P}<0.05)$, while the protein expression of TRPC6/TRPC7 was comparable between them. Compared with the control group, the protein expression of TRPC5 in the heart increased dramatically in the OSAHS group. This indicates that TRPC5 channel is likely to be involved in the myocardial pathophysiological changes caused by OSAHS (intermittent hypoxia), but the specific mechanism underlying the role of TRPC5 in the OSAHS is needed to be further studied, which would provide a new target for the clinical prevention and treatment of OSAHS related cardiac damage.

\section{Acknowledgments}

Funding: None.

\section{Footnote}

Conflicts of Interest: All authors have completed the ICMJE uniform disclosure form (available at http://dx.doi. org/10.21037/apm.2020.04.08). The authors have no conflicts of interest to declare.

Ethical Statement: The authors are accountable for all aspects of the work in ensuring that questions related 
to the accuracy or integrity of any part of the work are appropriately investigated and resolved. This study was approved by the Ethics Committee of Xinjiang Medical University (IACUC-20170214045).

Open Access Statement: This is an Open Access article distributed in accordance with the Creative Commons Attribution-NonCommercial-NoDerivs 4.0 International License (CC BY-NC-ND 4.0), which permits the noncommercial replication and distribution of the article with the strict proviso that no changes or edits are made and the original work is properly cited (including links to both the formal publication through the relevant DOI and the license). See: https://creativecommons.org/licenses/by-nc-nd/4.0/.

\section{References}

1. Niroumand M, Kuperstein R, Sasson Z, et al. Impact of Obstructive Sleep Apnea on Left Ventricular Mass and Diastolic Function. Am J Respir Crit Care Med 2001;163:1632-6.

2. Konishi T, Kashiwagi Y, Funayama N, et al. Obstructive sleep apnea is associated with increased coronary plaque instability: an optical frequency domain imaging study. Heart Vessels 2019;34:1266-79.

3. Gottlieb Daniel J YG, Newman Anne B. Prospective study of obstructive sleep apnea and incident coronary heart disease and heart failure: the sleep heart health study. Circulation 2010;122:352-60.

4. Geovanini G, Lorenzi-Filho G. Cardiac rhythm disorders in obstructive sleep apnea. J Thorac Dis 2018;10:S4221-30.

5. Leung RST. Sleep-disordered breathing: autonomic mechanisms and arrhythmias. Prog Cardiovasc Dis 2009;51:324-38.

6. Granger DN, Rutili G, McCord JM. Superoxide radicals in feline intestinal ischemia. Gastroenterology 1981;81:22-9.

7. Lavie L. Obstructive sleep apnoea syndrome--an oxidative stress disorder. Sleep Med Rev 2003;7:35-51.

8. Nerfeldt P, Friberg D. Effectiveness of Oral Appliances in Obstructive Sleep Apnea with Respiratory Arousals. J Clin Sleep Med 2016;12:1159-65.

9. Bompotis GC, Deftereos S, Angelidis C, et al. Altered calcium handling in reperfusion injury. Med Chem 2016;12:114-30.

10. Cioffi DL. Redox regulation of endothelial canonical transient receptor potential channels. Antioxid Redox
Signal 2011;15:1567-82.

11. Ren J, Liu W, Deng Y, et al. Losartan attenuates aortic endothelial apoptosis induced by chronic intermittent hypoxia partly via the phospholipase $\mathrm{C}$ pathway. Sleep Breath 2017;21:679-89.

12. Nilius B, Owsianik G. The transient receptor potential family of ion channels. Genome Biol 2011;12:218.

13. Philippaert K, Vennekens R. Chapter 19 - Transient Receptor Potential (TRP) Cation Channels in Diabetes. In: Szallasi A, editor. TRP Channels as Therapeutic Targets. Boston: Academic Press; 2015. p. 343-63.

14. Beech DJ. TRPC1: store-operated channel and more. Pflügers Archiv 2005;451:53-60.

15. Ahmad AA, Streiff M, Hunter C, et al. Physiological and pathophysiological role of transient receptor potential canonical channels in cardiac myocytes. Prog Biophys Mol Biol 2017;130:254-63.

16. Kumar B, Dreja K, Shah SS, et al. Upregulated TRPC1 channel in vascular injury in vivo and its role in human neointimal hyperplasia. Circ Res 2006;98:557-63.

17. Ohba T, Watanabe H, Murakami M, et al. Upregulation of TRPC1 in the development of cardiac hypertrophy. J Mol Cell Cardiol 2007;42:498-507.

18. Liu D, Yang D, He H, et al. Increased transient receptor potential canonical type 3 channels in vasculature from hypertensive rats. Hypertension 2009;53:70-6.

19. Harada M, Luo X, Qi XY, et al. Transient receptor potential canonical-3 channel-dependent fibroblast regulation in atrial fibrillation. Circulation 2012;126:2051-64.

20. Onohara N, Nishida M, Inoue R, et al. TRPC3 and TRPC6 are essential for angiotensin II-induced cardiac hypertrophy. EMBO J 2006;25:5305-16.

21. Chen GL, Jiang H, Zou F. Upregulation of transient receptor potential canonical channels contributes to endotoxin-induced pulmonary arterial stenosis. Med Sci Monit 2016;22:2679-84.

22. Francis $M, \mathrm{Xu} N$, Zhou $\mathrm{C}$, et al. Transient receptor potential channel 4 encodes a vascular permeability defect and high-frequency $\mathrm{ca}(2+)$ transients in severe pulmonary arterial hypertension. Am J Pathol 2016;186:1701-9.

23. He X, Li S, Liu B, et al. Major contribution of the 3/6/7 class of TRPC channels to myocardial ischemia/ reperfusion and cellular hypoxia/reoxygenation injuries. Proc Natl Acad Sci U S A 2017;114:E4582-91.

24. Fletcher EC, Lesske J, Qian W, et al. Repetitive, episodic hypoxia causes diurnal elevation of blood pressure in rats. Hypertension 1992;19:555-61. 
25. Belaidi E, Joyeux-Faure M, Ribuot C, et al. Major role for hypoxia inducible factor- 1 and the endothelin system in promoting myocardial infarction and hypertension in an animal model of obstructive sleep apnea. J Am Coll Cardiol 2009;53:1309-17.

26. Campbell SJ, Nery SV, Wardell R, et al. Water, Sanitation and Hygiene (WASH) and environmental risk factors for soil-transmitted helminth intensity of infection in Timor-Leste, using real time PCR. PLoS Negl Trop Dis 2017;11:e0005393.

27. Rodrigues ACM, Magalhães RD, Romcy KAM, et al. A new whole mitochondrial genome qPCR (WMG-qPCR) with SYBR Green® to identify phlebotomine sand fly blood meals. Vet Parasitol 2017;238:17-23.

28. Frosth S, König U, Nyman A-K, et al. Sample pooling for real-time PCR detection and virulence determination of the footrot pathogen Dichelobacter nodosus. Vet Res Commun 2017;41:189-93.

29. Yuan JP, Kim MS, Zeng W, et al. TRPC channels as STIM1-regulated SOCs. Channels 2009;3:221-5.

30. Nilius B, Flockerzi V. Mammalian transient receptor potential (TRP) cation channels. Preface. Handb Exp Pharmacol 2014;223:v-vi.

31. Sabourin J, Bartoli F, Antigny F, et al. Transient Receptor Potential Canonical (TRPC)/Orai1-dependent Storeoperated Ca2+ Channels: NEW TARGETS OF

Cite this article as: Wen W, Yao Q, Chen Y, Li Z, Maitikuerban B, Zhang Y, Zhang J, Simayi Z, Xu X, Zhang X. Transient receptor potential canonical 5 channel is involved in the cardiac damage related to obstructive sleep apnea-hypopnea syndrome in rats. Ann Palliat Med 2020;9(3):895-902. doi: 10.21037/apm.2020.04.08
ALDOSTERONE IN CARDIOMYOCYTES. J Biol Chem 2016;291:13394-409.

32. Sharma SH, Pablo JL, Montesinos MS, et al. Design, synthesis and characterization of novel N-heterocyclic1-benzyl-1H-benzo[d]imidazole-2-amines as selective TRPC5 inhibitors leading to the identification of the selective compound, AC1903. Bioorg Med Chem Lett 2019;29:155-9.

33. Zhang P, Liu X, Li H, et al. TRPC5-induced autophagy promotes drug resistance in breast carcinoma via CaMKK $\beta / \mathrm{AMPK} \alpha / \mathrm{mTOR}$ pathway. Sci Rep 2017;7:3158.

34. Ma X, Cai Y, He D, et al. Transient receptor potential channel TRPC5 is essential for P-glycoprotein induction in drug-resistant cancer cells. Proc Natl Acad Sci U S A 2012;109:16282-7.

35. Park SE, Song JH, Hong C, et al. Contribution of ZincDependent Delayed Calcium Influx via TRPC5 in Oxidative Neuronal Death and its Prevention by Novel TRPC Antagonist. Mol Neurobiol 2019;56:2822-35.

36. Hong C, Seo H, Kwak M, et al. Increased TRPC5 glutathionylation contributes to striatal neuron loss in Huntington's disease. Brain 2015;138:3030-47.

37. Sunggip C, Shimoda K, Oda S, et al. TRPC5-enos axis negatively regulates ATP-induced cardiomyocyte hypertrophy. Front Pharmacol 2018;9:523. 